\title{
ANALISIS PENERAPAN TEKNOLOGI PENANGGULANGAN HAMA PENYAKIT PADA USAHATANI CABAI MERAH DATARAN TINGGI DI PROVINSI BENGKULU
}

\section{Analysis of Technology Implementation of Pest and Disease on Highland Red Chili Farming in Bengkulu Province}

\author{
Herlena Bidi Astuti, Emlan Fauzi, Yahumri dan Rudi Hartono \\ Balai Pengkajian Teknologi Pertanian (BPTP) Bengkulu \\ Jl. Irian Km 6,5 38119, Telp (0736) 345568 \\ E-mail: bptp_bengkulu@yahoo.com \\ Website: www.bengkulu.litbang.pertanian.go.id
}

\begin{abstract}
Red chili is one of national strategic commodity, can affect the rate of inflation and is needed by all levels of society. Pest attack often makes low production and the high demand makes price of chili is very high. The aim of this study was to determine the application of pest management technology in farming chili crop in the highlands Province of Bengkulu. The research was conducted in Rejang Lebong and Lebong purposively determined by number of respondents as many as 62 people were taken by random sampling. The results showed an average score of application of crop pest management technology red chili is 2,38 meaning that the overall implementation of technology is not good. 37,5\% reduction technology implementation pepper plant pests and diseases in the category is not good that the use of biological pesticides, use of trap insect, and growing border. 37,5\% are categorized either using labeled seeds, sanitary land and land preparation is perfect. $25 \%$ excellent category that is sprayed with chemicals and use black plastic mulch silver.
\end{abstract}

Keywords: Application of Technology, Disease, Chili Farm and Highland

\section{PENDAHULUAN}

Cabai merupakan salah satu komoditas pertanian yang dibutuhkan dalam kehidupan sehari-hari. Kandungan senyawa cabai meliputi: kapsaikin, flavenoid, kapsisidin, kapsikol, dan minyak esensial. Selain itu cabai juga memiliki kandungan senyawa-senyawa dan kandungan gizi yang sangat berguna bagi tubuh. Cabai juga salah satu komoditas hortikultura penting di Indonesia yang tidak dapat dipisahkan dari kebutuhan sehari-hari rumah tangga tanpa memperhatikan tingkat sosial. Dimana kebutuhan akan cabai terus meningkat setiap tahun sejalan dengan meningkatnya jumlah penduduk dan berkembangnya industri yang membutuhkan bahan baku cabai. Selain itu cabai juga merupakan komoditas yang sangat berpengaruh dalam perekonomian yang kerap menjadi penyumbang inflasi sehingga kenaikan 
harga cabai tak boleh dianggap sepele. Harga cabai yang fluktuatif sehingga stabilitas harga sulit terjaga. Ironisnya, saat harga cabai naik harga barang lain pun ikut naik. Pada tahun 2015 deflasi tertinggi adalah bulan Februari sebesar 1,46 persen, dengan komoditas yang dominan menyumbangkan deflasi nasional pada bulan tersebut adalah turunnya harga cabai merah namun pada bulan Agustus Provinsi Bengkulu mengalami inflasi sebesar 1,99 dan salah satu penyebab utama inflasi adalah harga cabai di pasaran yang sangat tinggi, inflasi ini merupakan urutan kedua dari 82 Kota yang di pantau di Indonesia (BPS, 2015).

Bengkulu merupakan daerah yang dapat memproduksi cabai dengan baik, tahun 2014 produksi cabai segar dengan tangkai sebesar 46.166,70 ton dengan luas panen 7.432 hektar dengan rata-rata produktivitas 6,21 ton perhektar dibandingkan tahun 2013 produksi cabai di Bengkulu mengalami peningkatan 15,41 \% dengan luasan panen meningkat 28,34\%. Sedangkan produktivitas mengalami penurunan sebesar 0,70 ton perhektar (BPS, 2015). Penurunan produktivitas cabai ni bisa terjadi karena berbagai hal seperti perawatan tanaman yang meliputi pemupukan, sanitasi, pengairan dan yang paling banyak berpengaruh dalam penurunan produktivitas cabai adalah serangan hama dan penyaklit tanaman. Mulyani, dkk (2005) menjelaskan bahwa salah satu faktor pembatas dalam produksi cabai merah adalah gangguan Organisme Pengganggu Tanaman (OPT) khususnya hama dan penyakit, serangan hama dan penyakit tanaman tidak hanya menyebabkan penurunan produksi melainkan sampai mengakibatkan gagal panen.

Luasan panen cabai di Provinsi Bengkulu sebanyak $62 \%$ berada pada dataran tinggi dengan sentra di dua Kabupaten yaitu Kabupaten Rejang Lebong dan Kabupaten Lebong (BPS, 2014). Salah satu kelebihan dataran tinggi adalah hasil produksi bisa lebih banyak daripada cabai yang di tanam di dataran rendah. Akan tetapi permasalahan cabai dataran tinggi adalah kelembaban dan curah hujan yang tinggi menyebabkan serangan hama dan penyakit yang lebih banyak seperti busuk buah yang disebabkan oleh cendawan Colletotrichum spp. dan penyakit busuk daun fitoftora yang disebabkan oleh cendawan Phytophthora capsici (Moekasan dan Prabaningrum, 2011). Tujuan dari penelitian ini adalah untuk mengetahui penerapan teknologi penanggulangan hama dan penyakit tanaman cabai pada dataran tinggi di Bengkulu.

\section{METODE PENELITIAN}

Penelitian dilakukan pada bulan Maret sampai Juni 2015. Lokasi penelitian ditentukan secara purposive di sentra tanaman cabai dataran tinggi yaitu Desa Mojorejo Kabupaten Rejang Lebong dan Desa Mangku Rajo Kabupaten Lebong. Data yang diambil terdiri dari data primer dan data sekunder. Data primer meliputi karakteristik petani serta teknologi yang diterapkan oleh petani untuk menanggulangi serangan hama dan penyakit 
tanaman. Responden penelitian berjumlah 62 orang yang ditentukan secara simple random sampling dan data diambil dengan cara wawancara terhadap petani menggunakan kuesioner yang telah dibuat sebelumnya. Data sekunder merupakan data yang bersumber dari BPS dan dari Dinas Pertanian Provinsi Bengkulu dan Pemerintah Daerah.

Analisis data penerapan teknologi penerapan hama dan penyakit tanaman dilakukan dengan menggunakan interval kelas Amirullah dan Hadiyanti (2014) sebagai berikut:

NR = NST - NSR dan PI = NR : JIK

Keterangan:

NR : Nilai range

NST : Nilai skor tertinggi

NSR : Nilai skor terendah

JIK : Jumlah interval kelas

PI : Panjang interval kelas

Untuk 4 pilihan pertanyaan dengan penentuan nilai skor terendah adalah 1 dan skor tertinggi adalah 4 dapat ditentukan nilai range sebagai berikut: $\mathrm{NR}=4-1=3$

Panjang interval kelas $=0,75$ maka dapat di tentukan nilai interval kelas sebagai berikut:

Table 1. Nilai Interval Kelas

\begin{tabular}{ccc}
\hline No & Nilai Interval & Kesimpulan \\
\hline 1 & $1,00-1,75$ & Tidak baik \\
2 & $1,76-2,50$ & Kurang baik \\
3 & $2,51-3,25$ & Baik \\
4 & $3,26-4,00$ & Sangat baik \\
\hline
\end{tabular}

\section{HASIL DAN PEMBAHASAN}

\section{Karakteristik Responden}

Rata-rata umur petani responden adalah 37,4 tahun termasuk pada usia produktif dan usia pada angkatan kerja yang baik. Usia yang masih muda akan mempengaruhi semangat petani untuk mencari dan menerapkan teknologi baru begitu juga dengan pendidikan petani, semakin lama seseorang mendapatkan pendidikan formal akan semakin baik pula ia menerima berbagai informasi inovasi dan akan mempengaruhi hasil usahatani secara keseluruhan (Hutuaruk, 2009). Pengalaman petani cabai rata-rata 7,3 tahun artinya petani sudah lebih dari 5 kali melewati musim tanam cabai, lama pengalaman ini akan mempengaruhi keputusan dalam menanggulangi berbagai permasalahan selama proses produksi dijalankan. 
Rata-rata anggota keluarga adalah 5 orang yang terdiri dari 3 orang dewasa dan 2 orang anak-anak. Semakin banyak tanggungan semakin besar biaya yang harus dikeluarkan namun tanggungan keluarga yang termasuk pada usia produktif, jika dimanfaatkan secara optimal akan menjadi sumber tenaga kerja untuk membantu aktivitas usahatani keluarga. Semakin banyak tenaga kerja yang digunakan, maka semakin cepat usahatani tersebut selesai digarap. Banyaknya tenaga kerja dalam keluarga yang digunakan akan dapat menekan biaya produksi terutama menekan biaya tenaga kerja dari luar keluarga (Suratman, 2015).

Tabel 2. Karakteristik Responden Petani Cabai Dataran Tinggi

\begin{tabular}{clc}
\hline No & \multicolumn{1}{c}{ Uraian } & Rata-rata \\
\hline 1 & Umur (Tahun) & 37,4 \\
2 & Pendidikan (Tahun) & 8,9 \\
3 & Pengalaman (Tahun) & 7,3 \\
4 & Anggota keluarga (Orang) & \\
& - Dewasa & 3 \\
& - Anak - anak (<15 thn) & 2
\end{tabular}

Sumber: Data Primer setelah diolah, 2015

\section{Penerapan Teknologi Penanggulangan Hama Penyakit Tanaman Cabai Merah}

Hasil penelitian menunjukkan bahwa rata-rata skor penerapan teknologi penanggulangan hama penyakit tanaman (HPT) cabai merah adalah 2,38 artinya secara keseluruhan penerapan teknologi HPT kurang baik, dengan rincian setiap indikator sebagai berikut (Tabel 3).

Tabel 3. Penerapan Teknologi Penanggulangan Hama Penyakit Tanaman Cabai Merah

\begin{tabular}{clc}
\hline No & \multicolumn{1}{c}{ Indikator } & Skor \\
\hline 1. & Bibit berlabel & 2,97 \\
2. & Menggunakan mulsa & 3,73 \\
3. & Menggunakan pestisida kimia & 4,00 \\
4. & Menggunakan pestisida hayati & 1,00 \\
5. & Menggunakan perangkap serangga & 1,00 \\
6. & Menerapkan tanaman penghalang / border & 1,00 \\
7. & Pembersihan lahan & 2,55 \\
8. & Pengolahan tanah sempurna & 3,18 \\
\hline & \multicolumn{2}{r}{ Rata - rata }
\end{tabular}

Sumber : Data Primer setelah diolah, 2015

Dari Tabel 3 di atas dapat dilihat bahwa 37,5\% responden penerapan teknologi penanggulangan hama dan penyakit tanaman cabai berada pada kategori tidak baik yaitu penggunaan pestisida hayati, menggunakan perangkap serangga, dan menanam tanaman border. Sebanyak 37,5\%

130 | Herlena B.A., Emlan F., Yahumri, Rudi H., Analisis Penerapan Teknologi... 
responden masuk kategori baik yaitu menggunakan benih berlabel, sanitasi lahan dan pengolahan lahan sempurna. Sebanyak 25\% responden kategori sangat baik yaitu melakukan penyemprotan dengan bahan kimi dan menggunakan mulsa plastik hitam perak.

Pengadaan benih cabai dapat dilakukan dengan membuat sendiri atau membeli benih yang siap tanam namun sangat dianjurkan petani untuk memilih benih yang sudah bersertifikat karena selain praktis juga kualitas mutu terjamin (Cahyono, 2003). Penggunaan benih berlabel pada petani cabai merah berada pada skor 2,97 atau baik. Memilih menggunakan bibit berlabel merupakan langkah awal yang baik bagi petani cabai untuk menghindari serangan hama dan penyakit tanaman, Tjahjadi (1991) menjelaskan bahwa keberhasilan produksi cabai merah sangat dipengaruhi oleh kualitas benih yang dapat dicerminkan oleh tingginya produksi, ketahanan terhadap hama dan penyakit serta tingkat adaptasi iklim sehingga sangat dianjurkan petani menggunakan benih yang bersertifikat dan terjamin secara kualitas terhindar dari kontaminasi penyakit tanaman. Sejalan dengan hasil penelitian dari Wiratama dkk (2013), produktivitas dari varietas unggul bersertifikat (Tanjung) memiliki produktivitas tertinggi dibandingkan varietas lainnya termasuk varietas lokal.

Penggunaan mulsa pada usahatani cabai merah sudah sangat baik dengan skor nilai 3,73. Pemasangan mulsa plastik hitam perak merupakan salah satu usaha untuk mengoptimalkan kondisi lingkungan pertumbuhan tanaman yang lebih baik, sehingga tanaman dapat tumbuh dengan hasil produksi yang optimal. Pemulsaan dilakukan setelah dilakukan olah tanah dan dibuat bedengan serta sebelum bibit cabai ditanam. Pemulsaan ini bertujuan untuk memelihara struktur tanah, mengurangi pertumbuhan gulma, dan menekan serangan hama penyakit tanaman (Mulyani dkk, 2005). Menurut Pretty dan Hine dalam Setiawati dkk (2013), pemanfaatan mulsa merupakan salah satu usaha untuk penanggulangan hama penyakit pada tanaman cabai. Hasil penelitian Setiawati dkk (2013) juga menunjukkan bahwa rakitan PHT (varietas unggul, pemupukan dan penggunaan mulsa plastik perak) dapat menekan penggunaan pestisida sebesar $73,33 \%$ dengan hasil panen yang tetap tinggi yaitu 15,46 t/ ha. Mulsa juga tetap bisa digunakan pada musim kemarau karena pemaanfaatan mulsa akan mengurangi penguapan air tanah dan dapat mencegah kehilangan hasil sehingga hasil produksi tetap optimal (Norma dan Jauhari, 2008).

Penggunaan pestisida kimia berada pada skor 4,00 artinya semua petani menggunakan pestisida kimia untuk menanggulangi hama penyakit tanaman cabai merah. Berdasarkan konsepsi PHT (Suryaningsi dan Purbaningrum, 1998), pestisida hanya digunakan kalau memang benar-benar diperlukan (sesuai dengan hasil pengamatan egroekosistem). Selain itu, penggunaannya harus berhati-hati dan sekecil mungkin gangguannya terhadap lingkungan. Secara umum, penggunaan pestisida harus mengikuti lima kaidah, yaitu: (1) 
tepat sasaran, (2) tepat jenis, (3) tepat waktu, (4) tepat dosis/konsentrasi, (5) tepat cara penggunaan.

Penggunaan pestisida hayati, penggunaan perangkap serangga dan membuat tanaman border berada pada skor 1,00 artinya tidak ada petani yang menerapkan teknologi ini. Penerapan teknologi memerlukan adaptasi sekaligus keterampilan, demikian pula dengan penggunaan pestisida, ada banyak faktor yang harus diperhatikan, seperti indikasi hama, kapan saat menyemprot hama, takaran, teknik penyemprotan, dan lain-lain. Ironisnya, teknologi ini memiliki potensi bahaya khususnya pada saat kritis pencampuran. Banyak kasus dan penelitian yang sudah membuktikan banyak korban yang sudah berjatuhan akibat penggunaan pestisida, juga banyak ditemukan residu pestisida pada sayuran yang mengindikasikan pemakaian pestisida cukup intensif pada tingkat petani, hal ini pada umumnya dilakukan untuk mengurangi serangan hama dan penyakit yang menyerang tanamannya. Di sisi lain pestisida merupakan bahan kimia berbahaya, sehingga pemakaian yang berlebihan dapat menjadi sumber pencemar pada bahan pangan, air, dan lingkungan hidup. Lebih jauh residu yang ditinggalkan dapat secara langsung maupun tidak langsung sampai ke manusia (Miskiyah dan Munarso, 2009). Hasil penelitian Miskiyah dan Munarso (2009) menunjukkan bahwa sebagian besar residu pestisida yang terdeteksi pada sampel cabai merah menunjukkan bahwa pestisida dari golongan organoklorin dan organofosfat golongan pestisida organoklorin terdegradasi sangat lambat dan memerlukan waktu yang relatif lama, sedangkan golongan organofosfat sangat toksik namun mudah terdegradasi. Pemanfaatan pestisida hayati atau melakukan upaya pencegahan serangan hama dan penyakit secara ramah lingkungan seperti membuat tanaman border serta membuat perangkap serangga akan jauh lebih baik dan membuat hasil pertanian lebih layak konsumsi.

Sanitasi lahan berada pada skor 2,55 atau baik, sanitasi yang dimaksud adalah membersihkan lahan dari gulma atau tanaman pengganggu, gulma selain sebagai tanaman kompetitor juga dapat sebagai tempat berkembangnya hama dan penyakit tanaman cabai oleh karenanya penyiangan harus dilakukan untuk membersihkan daerah sekitar tanaman dari gulma. Selain itu sanitasi di maksudkan adalah membersihkan tanaman dan buah cabai yang jatuh karena infeksi hama dan penyakit untuk mencegah penularan atau perluasan serangan.

Pengolahan lahan yang baik dapat memberikan hasil yang optimal dan meningkatkan pendapatan petani cabai (Intara $d k k, 2011$ dan Depari, $d k k$ ), penerapan teknologi pengolahan lahan dengan sempurna berada pada skor 3,18 artinya penerapan teknologi pengolahan lahan sangat baik di tingkat petani. Pengolahan lahan dapat menghindari serangan hama dan penyakit dari tanah seperti ulat grayak dan jamur dapat dikurangi denga paparan sinar matahari ketika pengolahan lahan. 


\section{SIMPULAN}

Dari hasil penelitian dapat disimpulkan:

1. Rata-rata skor penerapan teknologi penanggulangan hama penyakit tanaman (HPT) cabai merah adalah 2,38 artinya secara keseluruhan penerapan teknologi HPT kurang baik.

2. Sebanyak $37,5 \%$ responden menerapkan teknologi penanggulangan hama dan penyakit tanaman cabai berada pada kategori tidak baik (penggunaan pestisida hayati, menggunakan perangkap serangga, dan menanam tanaman border). Sebanyak $37,5 \%$ responden masuk kategori baik (menggunakan benih berlabel, sanitasi lahan dan pengolahan lahan sempurna), dan 25\% responden berada pada kategori sangat baik yaitu melakukan penyemprotan dengan bahan kimi dan menggunakan mulsa plastik hitam perak.

\section{DAFTAR PUSTAKA}

Amirullah, Johanes dan Dedeh Hadiyanti. 2014. Keragaan Produksi Jarak Tanam dan Penerapan Teknologi Varietas Kentang (Solanum tuberosum

L.) pada Lahan Dataran Tinggi Provinsi Sumatera Selatan. Prosiding Seminar Nasional Lahan SubOptimal. Halaman 206-215.

BPS. 2015. Berita Resmi Statistik. No.46/08/17/Th IV, 03 Agustus 2015.http//www.bengkulu.bps.go.id.

BPS.2014. Bengkulu Dalam Angka. Badan Pusat Statistik Provinsi Bengkulu.

Cahyono, B. 2003. Teknik dan Strategi Budidaya Sawi Hijau (Pai-Tsai).

Yayasan Pustaka Nusantara. Yogyakarta.

Hutuaruk Erwin Husudungan. 2009. Pengaruh Pendidikan dan Pengalaman

Petani terhadap Tingkat Produktivitas Tanaman Kopi dan Kontribusi terhadap Pengembangan Wilayah di Kabupaten Tapanuli Utara. Tesis. Universitas Sumatera Utara (USU).

Intara Y.I., A. Sapei, Erizal, N. Sembiring, dan MUB Djoefrie. 2011. Mempelajari Pengaruh Pengolahan Tanah dan Cara Pemberian Air terhadap Pertumbuhan Tanaman Cabai. (Capsicum annum. L). Jurnal Embryo. Volume 8 No 1. Halamam 32-39.

Miskiyah dan S.J. Munarso. 2009. Kontaminasi Residu Pestisida pada Cabai Merah, Selada, dan Bawang Merah (Studi Kasus di Bandungan dan Brebes Jawa Tengah serta Cianjur Jawa Barat). Jurnal Hortikultura. Vol 19 No 1. Halaman 101-111.

Moekasan, K. Tonny dan Laksminiwati Prabaningrum. 2011. Budidaya Cabai Merah di Bawah Naungan untuk Menekan Serangan Hama dan Penyakit. Yayasan Bina Tani Sejahtera. Lembang. Jawa Barat.

Mulyani, E. Sujitno dan T. Fahmi. 2005. Pengenalan dan Pengendalian Hama

Penyakit Tanaman Cabai Merah. Monograf PTT Cabai Merah di Jawa Barat. BPTP Jawa Barat. 
Norma, Meniarti S., dan Jauhari Sodiq. 2008. Penerapan Irigasi Mikro, Tumpangsari dan Mulsa Untuk Mengantisipasi Kehilangan Hasil Cabai Merah Pada Penanaman di Musim Kemarau. Jurnal Agromet Indonesia. Vol 22. No 1.

Setiawati, W, N. Sumarni, Y. Koesandriani, A. Hasyim, T.S. Uhan dan R. Sutarya. 2013. Penerapan Teknologi Pengendalian Hama Terpadu pada Tanaman Cabai Merah untuk Mitigasi Dampak Perubahan Iklim. Jurnal Hortikultura. Volume 23. No 2. Halaman 174-183.

Suryaningsih, Euis dan L. Purbaningrum. 1998. Pestisida Selektif untuk Organisme Pengganggu Tumbuhan (OPT) pada Tanamamn Cabai. Monograf No 10. Balai Penelitian Tanaman Sayuran (BALITSA).

Suratman, Y.Y.A. 2015. Kontribusi Tenaga Kerja dalam Keluarga terhadap Pendapatan Usahatani Terong (Solanum melongenal L.) di Kelurahan Landasan Ulin Utara Kecamatan Liang Anggang Kota Banjar Baru. Jurnal Zira'ah Volume 40. No 30. Halaman 218-225.

Tjahjadi, Nur. 1991. Bertanam Cabai. Penerbit Kanisius. Yogyakarta.

Wiratama, I.D.M.P., I.P. Sudiarta, I.M. Sukewijaya, K. Sumiartha, dan M.P. Utama. 2013. Kajian Ketahanan Beberapa Galur dan Varietas Cabai Terhadap Serangan Antraknosa di Desa Abang Songan Kecamatan Kintamani Kabupaten Bangli. Jurnal Agroekoteknologi Tropika. Volume 2. No 2. Halaman 71-81. 